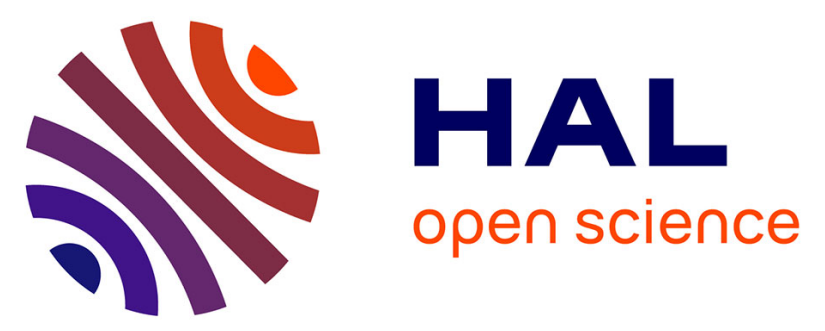

\title{
Patient-reported functional executive challenges and caregiver confirmation in adult brain tumor survivors
}

Nicole Cantisano, Philippe Menei, Vincent Roualdes, Romuald Seizeur,

Philippe Allain, Didier Le Gall, Arnaud Roy, Mickaël Dinomais, Jérémy

Besnard

\section{To cite this version:}

Nicole Cantisano, Philippe Menei, Vincent Roualdes, Romuald Seizeur, Philippe Allain, et al.. Patient-reported functional executive challenges and caregiver confirmation in adult brain tumor survivors. Journal of Cancer Survivorship, In press, 15, pp.696-705. 10.1007/s11764-020-00961-0 . hal-03014448

\section{HAL Id: hal-03014448 \\ https://hal-univ-tlse2.archives-ouvertes.fr/hal-03014448}

Submitted on 19 Nov 2020

HAL is a multi-disciplinary open access archive for the deposit and dissemination of scientific research documents, whether they are published or not. The documents may come from teaching and research institutions in France or abroad, or from public or private research centers.
L'archive ouverte pluridisciplinaire HAL, est destinée au dépôt et à la diffusion de documents scientifiques de niveau recherche, publiés ou non, émanant des établissements d'enseignement et de recherche français ou étrangers, des laboratoires publics ou privés. 


\section{Patient-reported functional executive challenges and caregiver confirmation in Adult Brain Tumor Survivors}

Cantisano, Nicole ${ }^{1}$, Menei, Philippe ${ }^{2}$, Roualdes, Vincent ${ }^{3}$, Seizeur, Romuald ${ }^{4}$, Allain, Philippe $^{5,6}$, Le Gall, Didier ${ }^{5,6}$, Roy, Arnaud ${ }^{6,7}$, Dinomais, Mickaël ${ }^{8}, \&$ Besnard, Jérémy $^{6}$

\section{Authors affiliations}

${ }^{1}$ Centre d'Etudes en Psychopathologie et Psychologie de la Santé (EA 7411), University of Toulouse Jean Jaurès, Toulouse, France

${ }^{2}$ Department of Neurosurgery, Angers University Hospital, Angers, France

${ }^{3}$ Department of Neurosurgery, Nantes University Hospital, Nantes, France

${ }^{4}$ Department of Neurosurgery, Brest Regional University Hospital, Brest, France

${ }^{5}$ Department of Neurology, Angers University Hospital, Angers, France

${ }^{6}$ Laboratoire de Psychologie des Pays de la Loire (EA 4638), University of Angers, Angers, France

7 Centre Référent des Troubles d'Apprentissage et Centre de Compétence Nantais de Neurofibromatose, Nantes University Hospital, France

${ }^{8}$ Department of Pediatric Physical Medicine and Rehabilitation, Angers University Hospital, Angers, France

\section{Fundings}

This study was supported by the French National Cancer Institute (INCa) (grant number SHSESP1414-041).

\section{Acknowledgments}

We wish to thank participants, families, and informants for their useful implication in this study.

We thank Hector Salcedo for his help in proofreading the current manuscript.

\section{Ethics approval}

The present study received French regulatory ethical approval (Comité de Protection des Personnes Ouest II, n'2015/27, ID-RCB n 2015-A01192-47) which includes the International Review Board Authorization ( ${ }^{\circ}$ NCT02693405).

\section{Consent to participate}

Informed consent was obtained from all individual participants included in the study.

\section{Consent to publish}

Participants signed informed consent regarding publishing their data.

\section{Conflicts of interest}

The authors have no conflict of interest to declare.

\section{Authors' contribution}

JB, PA and DLG contributed to the study conception and design. PM, VR, RS and MD recruited participants. Material preparation, data collection and analysis were performed by NC, AR and JB. JB supervised the project. NC and JB wrote the first version of the manuscript. All authors commented on the manuscript.

\section{Corresponding author}

Jeremy Besnard (ORCID: 0000-0001-7127-7558)

jeremy.besnard@univ-angers.fr 


\section{ABSTRACT}

Purpose. The main objective of this study was to provide further information concerning the validity of patient-reported executive function (EF) in survivors of primary brain tumor (PBT) compared with a report provided by each patient's caregiver.

Methods. Forty survivors of PBT, 40 non-cancer controls and their proxies completed an assessment of functional executive disorders (e.g., planning, inhibition, shifting and action initiation). Comparisons of self and informant EF reports were examined, for both patients and non-cancer controls. The extent of the concordance between patients' reports and their caregivers' reports was also determined.

Results. PBT survivors and their caregivers reported more problems related to EF in contrast with the non-cancer comparison group (significant differences). There was a high leyel of agreement between patients' and caregivers' ratings within the patient group

Conclusions. This study provides evidence suggesting that at an average of 3.67 (SD=2.31) years following treatment for a PBT, EF difficulties are reported by patients and their caregivers. This study establishes a consistency between what is reported by survivors and what is reported by those who frequently interact with them. Further research investigating the link between these ratings and quality of life as well as other functions is encouraged.

Implications for Cancer Survivors. This study's results demonstrate the importance of listening to PBT survivors' perception of EF difficulties. While not confirmed by neuropsychological evaluations, the functional executive challenges reported by these survivors' close relatives reflect what PBT survivors themselves report. Specialists should pay close attention to these difficulties in order to guarantee optimal post-cancer care.

Keywords. Functional executive deficits - Cancer survivorship - Primary Brain Tumor (PBT) - Cognitive late effects - BRIEF-A concordance

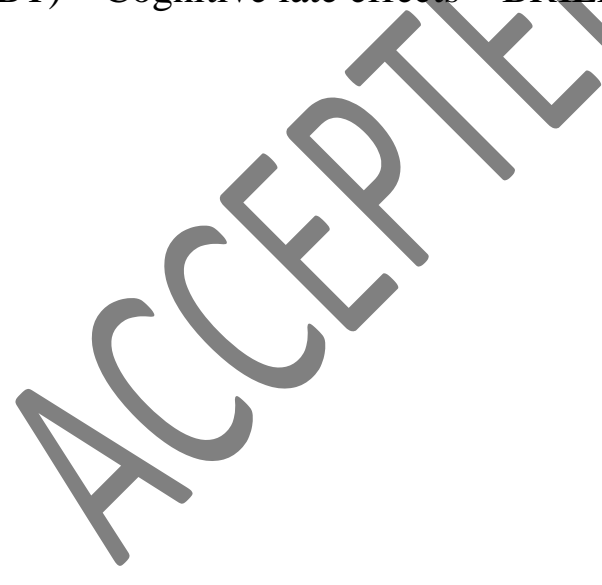




\section{INTRODUCTION}

Since 1970, there has been an increase in the prevalence of primary brain tumors (PBT) in developed countries [1, 2]. In France, for example, epidemiological estimates show an incidence rate of $15.5 / 105$ per 100,000 person-years [3]. Fortunately, due to significant advances in PBT treatment, there have been considerable improvements in survivorship. Recent data showed that the overall 5-year survival rate following a diagnosis of a PBT or central nervous system tumor reached $32.1 \%$ between 2000 and 2010 in the United States [4]. While these results are promising, they should not overshadow the fact that long-term adverse effects-referred to as 'late effect' - can occur in some brain tumor survivors [5, 6]. Several years after treatments end, the effects can persist or emerge - including medical, physical, cognitive and psychosocial sequelae. PBT survivors often experience late effects resulting from a combination of the effects of the tumor itself, and its associated treatments [7]. Among these late effects, cognitive dysfunction is one of the most serious challenges these patients face [8-11]. Few studies are deyoted to late cognitive effects in adult PBT survivors; these focus on a wide range of identified cognitive functions including attention, language, memory and executive function [e.g., 12, 71

One particularly important component of these cognitive domains is executive function (EF).Although there is not a consensus on the definition of these processes, Luria's seminal papers defined functions like planning, inhibition, shifting and action initiation as 'executive' [12], which are significantly involved in everyday life. A more contemporary and widely accepted definition of EF characterizes these functions as high-level cognitive processes assumed to underlie behavioral adaptation and regulation in daily life [13]. The main executive processes are inhibition, planning, initiation, rule detection, shifting, working memory and task coordination [e.g., 8, 14, 15]. Most daily life activities depend on the integrity of EF (e.g., shopping, scheduling activities, use of public transport, decision-making, 
work); therefore, executive difficulties can disrupt PBT patients' everyday lives and can negatively influence caregivers' lives [16].

For these reasons, EF measurement is of particular interest for clinicians (e.g., neuropsychologists, occupational therapists, rehabilitation doctors). Conventional assessment of EF is based on performance-based tasks, such as the Stroop interference test (inhibition measure) [17], the Tower of London (planning measure) [18] or the Modified Card Sorting Test (rule detection and set shifting measure) [19]. These tasks are administered by an examiner in highly standardized conditions, and measures usually involve response time, number of errors or patients' accuracy. Neuropsychological testing embodies the gold standard for assessing cognitive functions [20]. However, such performance-based tests sometimes are not feasible in busy clinics, and are not always sensitive to executive difficulties encountered by patients in eyeryday life [21, 22]. One explanation for the discrepancy between EF tasks and daily life executive functioning is that objective EF tasks are very constrained and well-structured, and therefore the ecological validity of actual functioning in life can be reduced [23, 24]. Another hypothesis is that traditional tasks examine component by component, thereby separating integrated executive processes without testing the multidimensional functional aspect implied in these processes [25]. It is also noteworthy that most EF performance-based tests were initially designed for assessment in non-patient populations [26]. To sum up, although these tasks are useful, they are insufficient to understand patients' executive difficulties in everyday life with adequate precision [27].

An alternative process for operationalizing and measuring EF involves rating scales, which include self and/or informant reports about executive difficulties when actually carrying out daily life activities. EF rating scales were created for the purpose of providing an ecologically valid measure of competence in complex everyday situations that involve 
executive functioning. Several measures for rating EF have been developed, such as the Dysexecutive Questionnaire [28], the Frontal Systems Behavior Scale [29], or the Behavioral Dysexecutive Syndrome Inventory [8]. As reported by Randolph and Chaytor [30], the most commonly used rating scale in adult populations is the Behavior Rating Inventory of Executive Function (BRIEF-A) [27]. Through performance-based tasks, these rating scales measure behaviors of underlying executive processes; however, a mismatch is frequently reported between formal neuropsychological testing and patient-reported measures. As pointed out by Toplak, West, and Stanovich [31], the performance-based tasks evaluate different processes than the rating EF measures, and therefore cannot be used interchangeably. While the objective of performance-based tasks is to provide useful information about the efficiency of processing, rating scales of EF are mostly associated with the ability to achieve goals, and therefore are linked to daily life activities $[32,33]$.

Few studies have examined EF in adult PBT survivors, and most of them used neuropsychological performance-based tasks $[7,10]$. Actually, data concerning the functional impact of EF challenges in this population are very scarce. This research gap is regrettable given the efficient and useful information that rating scales can provide when planning longterm care. In a few rare occasions, some studies have demonstrated executive limitations in adult PBT survivors by implementing self-reports, demonstrating that these difficulties may negatively impact the resumption of activities, including work $[34,35]$. Interestingly, EF selfreports seem more predictive of work output than traditional performance-based measures (in breast cancer survivors; [36]).

Contrary to cancer survivors who do not suffer from cerebral lesions, PBT survivors often exhibit cognitive difficulties and/or alterations in their awareness of deficits. It has been argued that this lack of awareness can affect the validity of self-report based assessments [37]. In order to test this assumption for the present study, the investigators sought informant 
reports from close relatives who are frequently engaged with PBT survivors, along with the self-reports completed by the PBT survivors themselves. The level of concordance between patients and caregivers (relatives) was presumed to provide evidence for the consistency of ratings and the presence of executive dysfunction in everyday life.

Since patients and their families are increasingly involved in personal health care decisions, it seems especially important for clinicians (1) to know how adult PBT survivors perceive their difficulties and whether there is any inconsistency in caregivers' perception of such difficulties, and (2) to better comprehend the long-term impact of functional challenges in PBT survivors. The primary objective of this study was to evaluate the functional executive challenges reported by PBT survivors and caregivers using the BRIEF-A. To reach this objective, self and informant EF reports were compared and evaluated in a PBT patient group (survivors), as well as a control group without any history of brain tumor or cancer (NonCancer Comparison Group; NCCG). First, it was hypothesized that in contrast to non-cancer controls, adult PBT survivors would report functional executive disorders. Second, patients' caregivers would confirm survivors' self-reports by indicating more executive disorders in daily-life activities than family members of the NCCG (informant reports). Third, according to previous data, a high level of agreement between self and caregiver reports in the patient group was expected $[38,39]$. It should be noted that there are only two very recent studies devoted to this topie in adult PBT patients. One of them examined executive self-assessment exclusively [35], while the other did not include the study of survivors [40].

\section{METHODS}

\section{Participants}

This study received French regulatory ethical approval (Comité de Protection des Personnes Ouest II, n²015/27, ID-RCB n²015-A01192-47) which includes the International 
Review Board Authorization ( ${ }^{\circ}$ NCT02693405). The Angers University Hospital was the study's promoter. Each participant signed an informed consent regarding their enrollment and future publishing of their anonymous data. Data were collected between June 2016 and December 2018.

Patients (PBT patient group; $n=40$ ) were recruited among neurosurgery departments in three university hospitals located in northwestern France. Eligibility regarding study criteria was verified by experienced physicians (PM, VR, RS and MD) before follow-up consultations. If they were eligible, patients were invited to participate in the study during these consultations, which included a neuropsychological assessment. Inclusion criteria were as follows: (1) patients had to be aged between 20 and 59 years to avoid the effect of normal aging on neurocognitive functioning; (2) they must have been treated (chemotherapy, radiation therapy or surgery) for a PBT. Patients with brain metastases of non-central nervous system tumors were not included. (3) As this study is devoted to functional late effects of PBT, patients should have completed their treatment at least two years prior to enrollment in the study. In addition, since the study's methodology (self-reports) requires a satisfactory level of understanding, (4) patients should not have presented major cognitive/understanding impairments, and (5) they had to be French native speakers. Medical data (tumor type and location, type of treatment, time since end of treatments) were collected and double-checked by NC and JB. Patients' illness information is presented on Table 1.

Non-cancer controls (NCCG; $n=40$ ) were recruited via a research center affiliated to one of the university hospitals. Inclusion criteria were identical to that of PBT patients in order to enable group matching (matching criteria: age, gender and educational level). Participants had to be aged between 20 and 59 years and French had to be their native language. In addition, based on participants' statements, they should not have had any history of severe psychiatric/neurological disease. Plausible participants were identified within the 
center's volunteer database and contacted by a nurse. If qualifying participants accepted, they were enrolled in the study.

\section{INSERT TABLE 1 ABOUT HERE}

After enrollment, within the hospital's premises and in a quiet room, patients and noncancer controls completed the self-report of the BRIEF-A and the brief neuropsychological evaluation. They also completed a questionnaire gathering socio-demographic data such as age, sex, educational level, professional status and laterality (Table 1). Before they returned to their homes, the informant version of the BRIEF-A was given to patients and to non-cancer controls, who were asked to transmit it to a proxy (e.g., family member, spouse). For the PBT patient group exclusively, the study's investigator called the caregiver a few days later to ask if he/she had any questions concerning the informant report. This also ensured that he/she had effectively completed the questionnaire. For each group, proxies had to mail back the questionnaire to the study's investigator after completion. No exclusion criteria were applied to the proxies.

\section{Measures}

Cognitive efficiency brief neuropsychological assessment

The level of global cognitive efficiency and understanding was checked with the MiniMental State Examination (MMSE; [41]) for both the PBT patient group and the NCCG. MMSE scores ranging between 25 and 30 (total range 0-30) are considered with normal limits.

\section{Daily-life executive functioning}

Self-report. To evaluate daily-life executive functioning, the self-rated version of the BRIEF-A was used ([27]; French version: [42]). The BRIEF-A is the questionnaire most widely used to highlight executive behavior problems relating to the performance of daily-life 
activities [30]. The self-reported questionnaire comprises 75 items that assess the frequency ('often,' 'sometimes,' or 'never') of different aspects of patients' executive functioning related problems within a 4-week time frame. Based on its factorial structure, the BRIEF-A provides both global and specific subdomains indices. A Global Executive Composite (GEC) can be obtained and broken down into two index scores: (1) the Behavioral Regulation Index (BRI) and (2) the Metacognition Index (MCI).

The BRI includes four clinical subscales. The Inhibit scale measures both inhibitory control and impulsivity -individuals' ability to resist impulses and to stop one's behavior at the appropriate time. The Shift scale assesses the capacity to meve easily from one situation to another as required by circumstances. The Emotional Control scale assesses an individual's ability to modulate or control his or her emotionalresponses. The Self-Monitor scale assesses aspects of social or interpersonal awareness. The MCI consists of five clinical subscales. The Initiate scale reflects an individual's ability to begin a task/activity and to independently produce ideas, responses, or problem-solving strategies. The Working Memory scale measures the ability to hold information in mind to accomplish a task. The Plan/Organize scale measures an individual's ability to manage current and future-oriented task demands. The Task Monitor scale reflects the ability to keep track of one's problem-solving success or failure and to identify and correct mistakes during behaviors. Finally, the Organization of Materials scale measures orderliness of work, living, and storage spaces.

Furthermore, the BRIEF-A [27, 42] assures the instrument's validity through three scales: Negativity (the extent to which the respondent answered items in an unusually negative manner), Unusual Answers (the extent to which the respondent endorsed items in an atypical manner) and Inconsistency (the extent to which the respondent erratically answered similar items). Concerning internal consistency, most BRIEF-A self-reported subscales presented satisfying Cronbach's alpha coefficients - except for Inhibition, Shift and Task-monitor scales 
which presented lower coefficients. All Cronbach's alpha coefficients are displayed on Table 2.

Informant-rated reports. As for the self-rated version, the informant report of the BRIEF-A comprises the same 75 items, which assess the frequency ('often,' 'sometimes,' or 'never') of different aspects of patients' executive functioning related problems within a 4week time frame. All BRIEF-A informant-reported validity scales Negativity, Unusual Answers and Inconsistency presented acceptable scores. Internal consistency for most BRIEFA informant reported subscales was likewise satisfying. The Inhibition and Self-monitor scales presented lower Cronbach's alpha coefficients (see Table 2).

\section{Data analysis}

Raw data were analyzed using STATISTICA Version 13.3 software (Tibco Software Inc, Palo Alto, CA, USA). First, one-tailed t-tests were conducted to compare each BRIEF-A self-report scale between the PTB patientgroup and the NCCG. Next, one-tailed $t$-tests were conducted to compare each BRIEF-A informant report scale between the PTB patient group and the NCCG. Finally, mean-split statistics were conducted within the PBT patient group to determine low and high scores, for both self-reports and informant-reports regarding the BRIEF-A. Pearson Chi Square tests were conducted to compare the frequency of low and high scores of these measures. The alpha level was retained at $p<.05$. For these explorative analyses, we did not correct for multiple testing.

\section{RESULTS}

Comparisons of self and informant reports of daily-life EF in patients and NCCG

In the PBT patient group, most caregivers were patients' spouses $(81.08 \%)$ or a close family member living with the patient (18.92\%). The informant reports for the NCCG were 
completed mainly by participants' spouses $(69.23 \%)$ or a close family member $(30.77 \%)$ living with the non-cancer control participant. Some informant report data was lost, especially in the NCCG (several participants' proxies did not return their questionnaires by mail). In the For the NCCG, the study's investigator did not call proxies; however, the caregivers for the PBT patient group were called by the investigator. Consequently, nine informant-reports were not mailed back for the NCCG (77.5\% response rate) and three were not mailed back for the PBT patient group (92.5\% response rate). Therefore, informant-report comparisons were conducted for 37 PBT patients and 31 non-cancer control participants for which all data sets were available.

The BRIEF-A self-reports displayed significant differences were found between the PBT patient group and the NCCG for the following subscales and indexes: Emotional Control, Working Memory, Task Monitor, Metacognition Index and Global Executive Composite. For all these subscales andindexes, the PBT patient group obtained higher scores, indicating more difficulties than non-cancer participants. Intergroup comparisons for the Behavioral Regulation Index did approach statistical significance (see Table 2).

In regards to the informant version of the BRIEF-A, significant differences were found between the PBT patient group and the NCCG for the following subscales and indexes: EmotionalControl, Self-Monitor, Working Memory, Behavioral Regulation Index and Global Executive Composite. For all these subscales and indexes, the PBT patient group obtained higher scores than the non-cancer participants. The differences between the PBT patient group and the NCCG for the Metacognition Index and Plan/Organize did approach statistical significance (see Table 2).

As for the global cognitive/understanding efficiency, the PBT patient group's mean MMSE score was $27.91(\mathrm{SD}=2.18)$ and the NCCG's was $28.58(\mathrm{SD}=1.81)$. No significant difference was found between groups $(t(69)=-1.41 ; p=.16)$. 
Overall ratings for both survivors and caregivers (PBT patient group)

Pearson Chi-Square tests using a median split (Table 3) showed no significant difference between low and high BRIEF-A categories $(n=40)$ and informant reports $(n=37)$. Low and high score frequencies for all BRIEF-A subscales and categories (self-reports and informant reports) are presented in Table 3.

\section{INSERT TABLE 3ABQUT HERE}

\section{DISCUSSION}

The present study aimed to evaluate functional challenges associated with the cognitive late effects of PBT, focusing on executive difficulties. Compared to matched participants in the NCCG, PBT survivors suffer from a negative impact of these functional executive challenges when carrying out activities of daily living. Correspondingly, a high level of concordance was observed between self- and caregiver- ratings of EF difficulties.

Patient-rated measures showed several impairments in daily EF domains: the Global Executive Composite and the Metacognitive index are significantly impaired compared to non-cancer controls' self-reports. Emotional control, working memory and task monitor constitute the three domains endorsed by PBT survivors as significant difficulties. These results are in line with those of a recent study, that employed BRIEF-A self-reports which demonstrated that working memory and task monitoring processes were among the most 
frequently reported as impaired by PBT patients [35]. The present study also included informant reports, which enabled the comparison between patients' and caregivers' perceptions regarding the impact of EF difficulties in daily life. Informants' reports universally support the results of PBT survivors' self-reports. It was observed that the Global Executive Composite and the Behavioral Regulation Index differed significantly between PBT survivors and non-cancer control participants. Particularly in concordance with their relatives, PBT survivors show increased difficulties in emotional control, working memory and self-monitoring compared to non-cancer controls.

To reiterate, self- and task-monitoring, working memory and emotional control seem the most affected domains by cognitive late effects of PBT. Moreover, working memory and emotional control are acknowledged as impaired by both patients and their caregivers. These results are consistent with those of previous studies using performance-based tasks, which report that executive dysfunction-including working memory impairment-comprises one of the most devastating cognitive sequelae of PBT [7]. The present results enhance these findings by demonstrating that executive disorders are likely to affect the ability to regulate and adapt behaviors in daily life. As to the difficulty to modulate and/or control emotional responses, it can be considered as new data in adult PBT survivors, and already observed in childhood PBT survivors [43].

At a clinical level, these findings support the usefulness of questionnaires such as BRIEF-A to orient survivorship care. While research devoted to PBT survivors is still at an early stage, rehabilitation of executive processes is feasible and well demonstrated in patients with acquired brain injury [44]. That being said, most cognitive interventions focus on the improvement of scores on performance-based tasks, hypothesizing that reducing cognitive impairments will reduce problems in everyday life. As recommended by the Society for Cognitive Rehabilitation [45], cognitive interventions must focus primarily on functional 
competence in real life. In this vein, the current study's results contribute by demonstrating that questionnaires can provide relevant information about the negative impact of cognitive sequelae in patients' daily life, which in turn is necessary for orienting cognitive interventions. They can help to target specific EF deficits endorsed by both patients and caregivers. At a later stage, questionnaires can also provide helpful indicators regarding the expected efficacy of interventions, by demonstrating (or not) a decrease in the difficulties experienced by patients. By highlighting specific daily EF difficulties in adult survivors of PBT, the results from this study contribute to guiding future research devoted to cognitive interventions in this population, which should focus on the real-life efficacy of the rehabilitation.

It is promising to note that no deficit was reported for several subscales of the BRIEFA. According to patients (self-reports) and caregivers (informant reports), inhibition, shifting, initiation, planning and organization skills seem preserved in the study's sample when compared to non-cancer controls. This means that executive competences may be selectively altered in PBT survivors, and that the late effects of the disease can be circumscribed to particular domains. This encouraging result contrasts conclusions brought forth by most previous publications devoted to the study of EF in adult PBT survivors, in which only difficulties on performance-based tasks are reported [e.g., 7, 10].

The third hypothesis was confirmed: comparisons between patients' self-reported measures and caregivers' reports showed a high level of concordance between both types of ratings, for all executive domains considered. This result fits well with that of a recent study published by Van der Linden et al. [40], which highlights a moderate level of agreement between patients with PBT and their proxies with the BRIEF-A. This study appears complementary to that study, which did not include survivors (on average, patients were recruited three months after surgery). The authors conclude that the proxy reports seem to 
constitute an adequate estimation of patients' reports. The present study's observations are fully in line with this conclusion, indicating that the everyday life functional difficulties reported by survivors' close relatives reflect what the PBT survivors themselves report.

Regarding implications for cancer survivors, it is recommended that specialists should pay serious attention to PBT survivors' perception of their difficulties, and therefore guarantee optimal post-cancer care. This assertion fits well with recent models and interventions devoted to survivorship care, which underscore the need to focus on patients' experience. Certainly, in a biopsychosocial perspective, it is necessary to separate the concept of disease — which refers to pathological biological processes - from that of illness, which refers to the patient's experience and representation of the disease. As stated recently by Leeper and Milbury [46], care processes should integrate the concept of illness (i.e., patient's representation) in order to be appropriately designed. They propose framework for survivorship care in neuro-oncology that lists several patient-reported outcomes to be considered, including cognitive status, as is measured in the present study.

Several potential limitations must be acknowledged. The first is that the PBT patient group is heterogeneous in regards to etiology, treatment, and lesion location. Although it can be considered that this heterogeneity is representative of what is found in clinical practice, the small sample size did not allow a valid statistical examination of the potential influence of these variables. Although this limitation is not specific to our study [e.g., 35, 40], a more homogenous and larger sample would enable more refined statistical analyses. It should be noted, however, that some studies have shown that the effect of chemotherapy or radiotherapy on cognitive functioning did not differ in patients with PBT, and that the addition of chemotherapy to radiotherapy has no influence on these variables [47]. Additionally, although the prevalence of cognitive deficits can vary according to tumor location or tumor type, most studies find that patients with PBT frequently encounter executive difficulties $[6,48,49]$. The 
present study was predominantly interested in the long-term impact of functional executive difficulties in PBT survivors, regardless of etiology and lesion location. Moreover, this study is one of the few in the field to include a group of patients who had completed their treatment for at least two years.

Several studies have demonstrated that self-cognitive assessments could be impacted by psychological distress, such as anxiety and depression [50]. Hence, another important limitation of this study is that psychological distress was not assessed; yet it is plausible that the high level of agreement between patients and informants' ratings helps to mitigate this flaw. Another variable that may modulate the level of agreement between patient and caregivers is patients' cognitive status. A low level of concordance was shown in patients with cognitive deficits [38]. In the present study, patients do not suffer from general cognitive deficits, as measured by the MMSE. These conclusions might have been different if patients had presented an alteration of cognitive efficiency, an assumption that needs further investigation. It should be noted however that Van der Linden et al. [40] recently contradict the conclusions of Ediebah et al. [38] by reporting no relationship between performance-based tests and patient-proxy agreement.

Despite the aforementioned limitations, this study provides new evidence regarding the impact of EF difficulties on PBT patients' daily functioning, which can be elicited several years after treatment ends. The present findings justify larger-scale prospective studies, in France and other countries, to confirm these preliminary results, and identify risk factors for EF challenges. This type of study should also be conducted with survivors of non-central nervous system cancers; while less severe than in patients with brain tumors, cognitive problems can exist and might affect significantly activities of daily life [36]. The high level of agreement between patients' and informants' ratings also validates the interest to consider patients' perception of their functional executive challenges, suggesting that survivors' ratings 
reflect what is observed by caregivers. In addition, the present results provide preliminary information necessary for the conception of cognitive interventions aimed at $\mathrm{EF}$ improvement.

\section{REFERENCES}

1. McNeill KA. Epidemiology of Brain Tumors. Neurologic Clinics. 2016;34(4):981-98.

2. Petruzzi A, Finocchiaro CY, Lamperti E, Salmaggi A. Living with a brain tumor. Support Care Cancer. 2013;21(4):1105-11.

3. Darlix A, Zouaoui S, Rigau V, Bessaoud F, Figarella-Branger D, MathieuDaudé H, et al. Epidemiology for primary brain tumors: a nationwide population-based study. $\mathrm{J}$ Neurooncol. 2017;131:525-46.

4. Barnholtz-Sloan JS, Ostrom QT, Cote D. Epidemiology of Brain Tumors. Neurologic Clinics. 2018;36(3):395-419.

5. Abu-Hegazy M, El-Hadaad HA. Neurocognitive Effects of Primary Brain Tumors. Neurooncology - Newer Developments. In Tech. 2016. p. 241-265

6. Meyers CA, Hess KR. Multifaceted end points in brain tumor clinical trials: Cognitive deterioration precedes MRI progression. Neuro Oneol. 2003;5(2):89-95.

7. Gehrke AK, Baisley MC, Sonck ALB, Wronski SL, Feuerstein M. Neurocognitive deficits following primary brain tumor treatment: systematic review of a decade of comparative studies. J Neurooncol. 2013;115(2):135-42.

8. Godefroy O, Azouyi P, Robert P, Roussel M, LeGall D, Meulemans T. Dysexecutive syndrome: Diagnostic criteria and validation study. Annals of Neurology. 2010; 68(6):855-64.

9. Lezak P of NP and NMD, Lezak MD, Howieson AP of N and PDB, Howieson DB, Loring $\mathrm{P}$ of NDW, Loring DW, et al. Neuropsychological Assessment. Oxford University Press; 2004. 1039 p.

10. Ng JCH, See AAQ, Ang TY, Tan LYR, Ang BT, King NKK. Effects of surgery on neurocognitive function in patients with glioma: a meta-analysis of immediate postoperative and long-term follow-up neurocognitive outcomes. J Neurooncol. 2019;141(1):167-82.

11. Abrey LE. The impact of chemotherapy on cognitive outcomes in adults with primary brain tumors. J Neurooncol. 2012; 108(2):285-90.

12. Lezak MD. The Problem of Assessing Executive Functions. International Journal of Psychology. 1982;17(1-4):281-97.

13. Miyake A, Friedman NP. The Nature and Organization of Individual Differences in Executive Functions: Four General Conclusions. Curr Dir Psychol Sci. 2012;21(1):8-14. 
14. Baddeley A. The episodic buffer: a new component of working memory? Trends in Cognitive Sciences. 2000;4(11):417-23.

15. Lieberman MD. Social: Why Our Brains are Wired to Connect. OUP Oxford; 2013.

16. Gregg N, Arber A, Ashkan K, Brazil L, Bhangoo R, Beaney R, et al. Neurobehavioural changes in patients following brain tumour: patients and relatives perspective. Support Care Cancer. 2014;22(11):2965-72.

17. Stroop JR. Studies of interference in serial verbal reactions. Journal of Experimental Psychology: General. 1992;121(1):15-23.

18. Shallice T, Broadbent DE, Weiskrantz L. Specific impairments of planning. Philosophical Transactions of the Royal Society of London B, Biological Sciences. 1982;298(1089):199-209.

19. Nelson HE. A Modified Card Sorting Test Sensitive to Frontal Lobe Defects. Cortex. 1976;12(4):313-24.

20. Buchanan T. Self-report measures of executive function problems correlate with personality, not performance-based executive function measures, in nonclinical samples. Psychol Assess. 2016;28(4):372-85.

21. Eslinger PJ, Damasio AR. Severe disturbance of higher cognition after bilateral frontal lobe ablation: Patient EVR. Neurology. 1985; 35(12):1731-1741. https://doi.org/10.1212/WNL.35.12.1731

22. Goldstein LH, Bernard S, Fenwick PB, Burgess PW, McNeil J. Unilateral frontal lobectomy can produce strategy application disorder. Journal of Neurology, Neurosurgery \& Psychiatry. 1993;56(3):274-6.

23. Salthouse TA. Interrelations of Aging, Knowledge, and Cognitive Performance. In: Staudinger UM, Lindenberger U, éditeurs. Understanding Human Development: Dialogues with Lifespan Psychology . Boston, MA: Springer US; 2003. p. 265-87. https://doi.org/10.1007/978-1-4615-0357-6_12

24. Burgess PW, Alderman N, Volle E, Benoit RG, Gilbert SJ. Mesulam's frontal lobe mystery re-examined. Restorative Neurology and Neuroscience. 2009;27(5):493-506.

25. Burgess PW, Alderman N, Evans J, Emslie H, Wilson BA. The ecological validity of tests of executive function. Journal of the internation neuropsychological society. 1998;4(6):547-558.

26. Burgess PW, Alderman N, Forbes C, Costello A, M-A.coates L, Dawson DR, et al. The case for the development and use of "ecologically valid" measures of executive function in experimental and clinical neuropsychology. Journal of the International Neuropsychological Society. 2006;12(2):194-209.

27. Roth RM, Isquith PK, Gioia GA. BRIEF-A: Behavior rating inventory of executive function—adult version: Professional Manual. Psychology Assessment Resources. 2005.

28. Wilson BA, Evans JJ, Alderman N, Burgess PW, Emslie H, Evans JJ, et al. Behavioural 
Assessment of the Dysexecutive Syndrome. Methodology of Frontal And Executive Function. 2004.

29. Grace J, Malloy PF. Frontal systems behavior scale: Professional manual. Psychological Assessment Resources. 2001.

30. Randolph JJ, Chaytor NS. Promoting the Executive Functions: Core Foundations, Assessment Considerations, and Practical Applications. In: Randolph JJ, éditor. Positive Neuropsychology: Evidence-Based Perspectives on Promoting Cognitive Health. New York, NY: Springer; 2013.

31. Toplak ME, West RF, Stanovich KE. Practitioner Review: Do performance-based measures and ratings of executive function assess the same construct? Journal of Child Psychology and Psychiatry. 2013;54(2):131-43.

32. Barkley RA, Murphy KR. The Nature of Executive Function (EF) Deficits in Daily Life Activities in Adults with ADHD and Their Relationship to Performance on EF Tests. J Psychopathol Behav Assess. 2011;33(2):137-58.

33. Chevignard MP, Soo C, Galvin J, Catroppa C, Eren S. Ecological assessment of cognitive functions in children with acquired brain injury: A systematic review. Brain Injury. 2012;26(9):1033-57.

34. Collins C, Gehrke A, Feuerstein M. Cognitive Tasks Challenging Brain Tumor Survivors at Work. Journal of Occupational and Environmental Medicine. 2013;55(12):1426-1430.

35. Loughan AR, Braun SE, Lanoye A. Executive dysfunction in neuro-oncology: Behavior Rating Inventory of Executive Function in adult primary brain tumor patients. Applied Neuropsychology: Adult. 2019;0(0):1-10.

36. Calvio L, Peugeot M, Bruns GL, Todd BL, Feuerstein M. Measures of Cognitive Function and Work in Occupationally Active Breast Cancer Survivors. Journal of Occupational and Environmental Medicine. 2010;52(2):219-227.

37. Molinari, E, Mendoza, TR, Gilbert, MR. Opportunities and challenges of incorporating clinical outcome assessments in brain tumor clinical trials. Neurooncol Pract. 2019; $6(2): 81-92$.

38. Ediebah DE, Reijneveld JC, Taphoorn MJB, Coens C, Zikos E, Aaronson NK, et al. Impact of neurocognitive deficits on patient-proxy agreement regarding health-related quality of life in low-grade glioma patients. Qual Life Res. 2017;26(4):869-80.

39. Jacobs DI, Kumthekar P, Stell BV, Grimm SA, Rademaker AW, Rice L, et al. Concordance of patient and caregiver reports in evaluating quality of life in patients with malignant gliomas and an assessment of caregiver burden. Neurooncol Pract. 2014;1(2):47-54.

40. van der Linden SD, Gehring K, Baene WD, Emons WHM, Rutten G-JM, Sitskoorn MM. Assessment of Executive Functioning in Patients with Meningioma and Low-Grade Glioma: A Comparison of Self-Report, Proxy-Report, and Test Performance. Journal of the International Neuropsychological Society. 2020;26(2):187-96. 
41. Folstein M. A practical method for grading the cognitive state of patients for the children. J Psychiatr Res. 1975;12:189-98.

42. Roy A, Besnard J, Lancelot C, Le Gall D. Adaptation and validation in French of the Behavior Rating Inventory of Executive Function- Adult Version (BRIEF-A). Paris: Hogrefe; 2015.

43. Ellenberg L, Liu Q, Gioia G, Yasui Y, Packer RJ, Mertens A, et al. Neurocognitive status in long-term survivors of childhood CNS malignancies: A report from the Childhood Cancer Survivor Study. Neuropsychology. 2009;23(6):705-17.

44. Tornås S, Løvstad M, Solbakk A-K, Evans J, Endestad T, Hol PK, et al. Rehabilitation of Executive Functions in Patients with Chronic Acquired Brain Injury with Goal Management Training, External Cuing, and Emotional Regulation: A Randomized Controlled Trial. Journal of the International Neuropsychological Society. 2016;22:436-52.

45. Society for Cognitive Rehabilitation. "What Is Cognitive Rehabilitation?" 2013. www.societyforcognitiverehab.org.

46. Leeper H; Milbury K. Survivorship care planning and implementation in neurooncology. Neuro-Oncology. 2018; 20:vii40-vii46.

47. Reijneveld JC, Taphoorn MJB, Coens C, Bromberg JEC, Mason WP, Hoang-Xuan K, et al. Health-related quality of life in patients with high-risk low-grade glioma (EORTC 22033-26033): a randomised, open-label, phase 3 intergroup study. The Lancet Oncology. 2016;17(11):1533-42.

48. Richard NM, Bernstein LJ, Mason WR, Laperriere N, Maurice C, Millar B-A, et al. Cognitive rehabilitation for executive dysfunction in brain tumor patients: a pilot randomized controlled trial.J Neurooncol. 2019;142(3):565-75.

49. Tringale KR, Nguyen T, Bahrami N, Marshall DC, Leyden KM, Karunamuni R, et al. Identifying early diffusion imaging biomarkers of regional white matter injury as indicators of executive function decline following brain radiotherapy: A prospective clinical trial in primary brain tumor patients. Radiotherapy and Oncology. $2019 ; 132: 27-33$.

50. Nicol C, Qwnsworth T, Cubis L, Nguyen W, Foote M, Pinkham MB. Subjective cognitive functioning and associations with psychological distress in adult brain tumour survivors. J Cancer Surviv. 2019;13(5):653-62. 
Table 1. Participants' socio-demographic data and clinical characteristics of PBT patients.

\begin{tabular}{|c|c|c|}
\hline Characteristic & $\begin{array}{c}\text { PBT Patients } \\
(n=40)\end{array}$ & $\begin{array}{c}\text { NCC } \\
(n=40)\end{array}$ \\
\hline & Mean ( \pm SD) / Number $(\%)$ & Mean \pm SD / Number $(\%)$ \\
\hline Age (Years) & $41.20(11.06)$ & $40.88(11.06)$ \\
\hline \multicolumn{3}{|l|}{ Gender } \\
\hline Men & $28(70 \%)$ & $25(63 \%)$ \\
\hline Women & $12(30 \%)$ & $15(37 \%)$ \\
\hline \multicolumn{3}{|l|}{ Laterality } \\
\hline Left handed & $5(12.5 \%)$ & $2(5 \%)$ \\
\hline Right handed & $34(85 \%)$ & $36(90 \%)$ \\
\hline Ambidextrous & $1(2.5 \%)$ & \\
\hline Bilingual & $4(10 \%)$ & 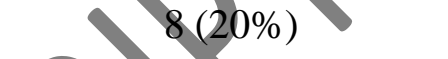 \\
\hline Visual aid (glasses) & $25(62.5 \%)$ & \\
\hline Education (Years)* & $11.83(3.29)$ & \\
\hline End of treatments (Years) & $3.67(2.31)$ & \\
\hline \multicolumn{3}{|l|}{ Tumor Diagnosis } \\
\hline Oligodendroglioma & $11(27.5 \%)$ & -- \\
\hline Oligoastrocytoma & & -- \\
\hline Astrocytoma & & -- \\
\hline Glioblastoma & & -- \\
\hline Glioma & & -- \\
\hline Other tumors** & & \\
\hline \multicolumn{3}{|l|}{ Treatments } \\
\hline Chemotherapy & & -- \\
\hline Radiotherapy & & -- \\
\hline Tumor Resection & $39(97.5 \%)$ & \\
\hline
\end{tabular}

Note. *Number of years after $1{ }^{\text {st }}$ grade (elementary school); **Craniopharyngioma, Meningioma, Medulloblastoma, Subependymoma, Neurocytoma, Germinoma. 
Table 2. Group comparisons for BRIEF-A self-reports and informant reports.

\begin{tabular}{|c|c|c|c|c|c|}
\hline & $\begin{array}{c}\text { PBT Patients } \\
\text { Mean (SD) }\end{array}$ & $\begin{array}{c}\text { NCC } \\
\text { Mean (SD) }\end{array}$ & $t$ & $d f$ & $p$ \\
\hline BRIEF-A Self Report & $\mathrm{n}=40$ & $\mathrm{n}=40$ & & & \\
\hline Inhibition $(\alpha=.58)$ & $51.95(11.43)$ & $50.48(8.81)$ & .65 & 78 & .52 \\
\hline Shift $(\alpha=.66)$ & $52.20(10.83)$ & $40.48(10.42)$ & 1.15 & 78 & .26 \\
\hline Emotional Control $(\alpha=.89)$ & $51.55(12.36)$ & $46.38(9.48)$ & 2.10 & 78 & .04 \\
\hline Self-Monitor $(\alpha=.80)$ & $51.40(14.61)$ & $48.08(8.77)$ & 1.23 & 78 & .22 \\
\hline Initiate $(\alpha=.71)$ & $50.63(14.03)$ & $48.20(9.34)$ & & 78 & .37 \\
\hline Working Memory $(\alpha=.83)$ & $57.00(13.85)$ & $49.30(10.94)$ & & 78 & .007 \\
\hline Plan/Organize $(\alpha=.76)$ & $51.10(12.99)$ & $48.25(9.42)$ & & 78 & .27 \\
\hline Task Monitor $(\alpha=.60)$ & $54.05(11.59)$ & $48.40(8.38)$ & & 78 & .01 \\
\hline Organization of Materials $(\alpha=.82)$ & $49.60(10.66)$ & $47.07(9.44)$ & & 78 & .27 \\
\hline Behavioral Regulation Index (BRI) & $52.28(12.78)$ & $47.63(8.85)$ & & 78 & .07 \\
\hline Metacognition Index (MCI) & $53.20(12.17)$ & $47.90(9.21)$ & 20 & 78 & .03 \\
\hline Global Executive Composite (GEC) & $53.13(12.10)$ & & 2.44 & 78 & .02 \\
\hline Negativity scale & $0.55(1.04)$ & 43) & -- & -- & -- \\
\hline Unusual answers scale & $0.70(0.76)$ & & -- & -- & -- \\
\hline Inconsistency scale & 3.45 & & -- & -- & -- \\
\hline \multicolumn{6}{|l|}{ BRIEF-A Informant Report } \\
\hline Inhibition $(\alpha=.49)$ & & $10(7.86)$ & 1.42 & 66 & .16 \\
\hline Shift $(\alpha=.74)$ & & $45.65(8.84)$ & 1.20 & 66 & .24 \\
\hline Emotional Control $(\alpha=.88)$ & & $44.90(8.42)$ & 2.31 & 66 & .02 \\
\hline Self-Monitor $(\alpha=.55)$ & & $44.35(7.41)$ & 2.14 & 66 & .04 \\
\hline Initiate $(\alpha=.84)$ & 32) & $46.68(12.51)$ & 0.94 & 66 & .35 \\
\hline Working Memo & $.77)$ & $45.96(7.75)$ & 2.39 & 66 & .02 \\
\hline Plan/Organize $(o$ & $16(11.71)$ & $46.45(8.63)$ & 1.86 & 66 & .07 \\
\hline Task Monit & $51.14(9.81)$ & $46.84(12.39)$ & 1.60 & 66 & .12 \\
\hline Organization & $47.70(7.35)$ & $46.32(10.13)$ & 0.64 & 66 & .52 \\
\hline Behavioral Regulation Index (BRI) & $48.73(8.84)$ & $44.09(8.09)$ & 2.23 & 66 & .03 \\
\hline Metacognition Index (MCI) & $50.27(9.77)$ & $45.65(9.90)$ & 1.93 & 66 & .06 \\
\hline Global Executive Composite (GEC) & $49.22(9.73)$ & $44.29(9.22)$ & 2.12 & 66 & .03 \\
\hline Negativity scale & $0.41(0.93)$ & $0.15(0.36)$ & -- & -- & -- \\
\hline Unusual answers scale & $0.70(0.78)$ & $1.72(1.00)$ & -- & -- & -- \\
\hline Inconsistency scale & $3.27(1.66)$ & $2.09(1.21)$ & -- & -- & -- \\
\hline
\end{tabular}

Note. $\alpha=$ Cronbach's alpha; SD=standard deviations; Significant values are in bold; *decrease in the number of participants given proxy lost data 
Table 3. Comparisons between PBT patients' and their caregivers' executive function ratings.

\begin{tabular}{|c|c|c|c|c|}
\hline BRIEF-A Subscales & $\begin{array}{c}\text { Self-Report } \\
n=40 \\
\mathrm{~N}(\%)\end{array}$ & $\begin{array}{c}\text { Informant Report } \\
n=37 \\
\mathrm{~N}(\%)\end{array}$ & Pearson Chi-square & $p$ \\
\hline Inhibit & & & .01 & .92 \\
\hline Low & $19(47.50)$ & $18(48.65)$ & & \\
\hline High & $21(52.50)$ & $19(51.35)$ & & \\
\hline Shift & & & .02 & .89 \\
\hline Low & $19(47.50)$ & $17(45.95)$ & & \\
\hline High & $21(52.50)$ & $20(54.05)$ & & \\
\hline Emotional Control & & & & .72 \\
\hline Low & $20(50)$ & $17(45.95)$ & & \\
\hline High & $20(50)$ & $20(54.05)$ & & \\
\hline Self Monitor & & & & .55 \\
\hline Low & $20(50)$ & $16(43.24)$ & & \\
\hline High & $20(50)$ & $21(56.76)$ & & \\
\hline Initiate & & & .25 & .62 \\
\hline Low & $14(35)$ & & & \\
\hline High & $26(65)$ & 6) & & \\
\hline Working Memory & & & .04 & .91 \\
\hline Low & $20(50)$ & 55) & & \\
\hline High & $20(50)$ & 35) & & \\
\hline Plan/Organize & & & .28 & .60 \\
\hline Low & $f(0)$ & $17(45.95)$ & & \\
\hline High & & $20(54.05)$ & & \\
\hline Task Monitor & & & .78 & .38 \\
\hline Low & & $13(35.14)$ & & \\
\hline High & $22(55)$ & $24(64.86)$ & & \\
\hline Organization of $\mathrm{M}$ & & & .16 & .69 \\
\hline Low & $18(45)$ & $15(40.54)$ & & \\
\hline High & $22(55)$ & $22(59.46)$ & & \\
\hline Behavioral Regulat & & & .13 & .72 \\
\hline Low & $20(50)$ & $17(45.95)$ & & \\
\hline High & $20(50)$ & $20(54.05)$ & & \\
\hline Metacognition Index & & & .01 & .92 \\
\hline Low & $21(52.21)$ & $19(51.35)$ & & \\
\hline High & $19(47.50)$ & $18(48.65)$ & & \\
\hline $\begin{array}{l}\text { Global Executive Co } \\
\text { (GEC) }\end{array}$ & & & .35 & .55 \\
\hline Low & $20(50)$ & $16(43.24)$ & & \\
\hline High & $20(50)$ & $21(56.76)$ & & \\
\hline
\end{tabular}

Note. Median split : Low $=$ under median; High = over median 